\title{
É HORA DO SHOW: A CONDUTA DE PROFISSIONAIS DA TELEVISÃO DE ACORDO COM O CÓDIGO DE ÉTICA DO JORNALISTA E CÓDIGO PENAL BRASILEIRO
}

\author{
Alan Araujo Barbosa ${ }^{1}$ \\ Flávia Mota ${ }^{2}$
}

\begin{abstract}
RESUMO
O artigo tem por objetivo abordar a conduta de profissionais da comunicação brasileira, tanto no âmbito regional quanto no nacional. No primeiro caso, tratase da reportagem "Chororô na delegacia: acusado de estupro alega inocência", realizada pela repórter Mirella Cunha do programa Brasil Urgente Babia da BAND Bahia, e no segundo caso é colocada em questão a análise do vídeo "Sê Tu Uma Benção", feita pelo apresentador Carlos Massa em seu programa de entretenimento no SBT. Dessa maneira, procuramos identificar se as infrações cometidas podem ser enquadradas nos crimes de injúria, calúnia e difamação, mais comumente atribuídos aos profissionais do jornalismo brasileiro, tudo dentro das transgressões do Código Penal.
\end{abstract}

Palavras-chave: Televisão. Jornalismo. Sensacionalismo. Ética. Código Penal.

\footnotetext{
${ }^{1}$ Graduando do VI Período em Comunicação Social e Jornalismo da Universidade Estadual do Sudoeste da Bahia (UESB), bolsista FAPESB no projeto de pesquisa e extensão: Jornalismo, Cidade e Patrimônio Cultural. E-mail: alanaraujo.br@hotmail.com.

${ }^{2}$ Mestre em Linguística pela UESB e docente do curso de Comunicação Social e Jornalismo da UESB. E-mail: flaviamotamota@gmail.com
} 


\begin{abstract}
The article aims to address the conduct of the Brazilian communication professionals both at the regional level, as the national. In the first case, it is the story "Too cry in delegacy: accused of rape claims innocence" performed by Mirella Cunha of the Brasil Urgente Babia program from BAND Bahia, and in the second case questioned the analysis of the video "Be Thou a Blessing" performed by the presenter Carlos Massa in his entertainment program in SBT . In this way, we seek to identify whether the infractions can be framed in injury crimes, slander and libel, Code, more commonly attributed to professionals in the Brazilian journalism, all within the transgressions of the Criminal.
\end{abstract}

Keywords: Television. Journalism. Sensationalism. Ethics. Penal Code.

\title{
Introdução
}

Além de ser uma distração, a televisão já se tornou um aparelho que viabiliza a difusão de conhecimento, informação e união entre as diversas classes sociais, transformando-se em um instrumento que consegue influenciar e proporcionar a deliberação de assuntos muitas vezes considerados importantes.

Embora a transformação de algo rotineiro em espetáculo faça parte até mesmo dos programas da linha shows ou de entretenimento, como também são conhecidos, atualmente as emissoras de televisão (TV) vêm transformando os programas da linha de "shows" em programas sensacionalistas, em razão dos interesses de grande parte dos telespectadores por tais programas.

Segundo Marcondes Filho (1986), o sensacionalismo jornalístico funciona como um nutriente ideológico que se caracteriza por impulsionar a comercialização da informação, se apropriando apenas da aparência para construir a notícia almejada, e afirma: "No fundo a imprensa sensacional trabalha com a emoção, da mesma maneira que os regimes totalitários trabalham com o fanatismo, também de natureza puramente emocional".

Pedroso afirma que: 
(A imprensa sensacionalista) não se presta a informar, muito menos a formar. Presta-se básica e fundamentalmente a satisfazer a necessidade instintiva do público, por meio de formas sádicas, caluniadora e ridicularizadora das pessoas. Por isso, a imprensa sensacionalista, como a televisão, o papo no bar, o jogo de futebol, servem mais para desviar o público de sua realidade imediata do que para voltar-se a ela, mesmo que fosse para fazê-lo adaptar-se a ela (PEDROSO, 1983, p. 15).

As notícias que se caracterizam como "notícias shows" conseguem transformar os acontecimentos sociais em simples diversão, esvaziando a crítica do jornalismo, tapando buracos do tempo do programa com assuntos irrelevantes, além de omitir, mostrando. Confirmando, desta forma, o que Bourdieu já havia afirmado em seu livro Sobre a televisão: "O tempo é extremamente raro na televisão, e minutos tão preciosos são empregados para dizer coisas fúteis, é que essas coisas tão fúteis são de fato importantes que conseguem ocultar coisas preciosas" (BOURDIEU, 1997, p. 27).

\section{A televisão e sua nova característica}

Como consequência dos avanços tecnológicos, os programas televisivos tiveram que se adequar às novas tecnologias e se aproximar de uma nova e avançada concorrente, a internet, que nasce com o intuito de acoplarem a um só aparelho todo o tipo de comunicação social que até o momento existe. Assim sendo, a TV, além de se adequar a essa nova e poderosa concorrente, passou a ter como principal característica o recurso "Ao Vivo", ou a instantaneidade, que se refere à capacidade de mostrar a notícia no momento em que está acontecendo. Nesse caso, a mensagem é exibida de forma rápida, sendo assimilados de uma só vez, quando emitida, a facilidade de penetração, pois tem a capacidade de atingir todas as camadas da população; a superficialidade, que diz respeito aos problemas do tempo, compromissos comerciais e a constante concorrência por audiência, que impedem os telejornais 
de abordarem os fatos apresentados com mais profundidade; e, por fim, o envolvimento, que se refere à ilusão que a televisão produz no telespectador com as mensagens narrativas.

Apesar da sua função social, a televisão sempre é acusada, principalmente pela classe acadêmica, por ter a capacidade de manipular a sociedade devido ao seu poder ditatorial no que diz respeito a impor regras e valores.

\section{Sensacionalismo}

Ferreira (2004, p. 666), afirma que o termo "sensacionalismo" é um substantivo masculino que conota a 1. Divulgação e exploração, com tom espalhafatoso, de matéria capaz de emocionar ou escandalizar; 2. Uso de atitudes chocantes, hábitos exóticos etc.; 3. Exploração do que é sensacional na literatura, na arte etc. Enquanto que o termo "Sensacionalista" refere-se a uma Adjetivação de 2g. Em "que há, ou que usa de sensacionalismo; notícia sensacionalista; jornal sensacionalista".

Angrimani (1995), afirma que não importa qual seja o contexto, sempre que se quer acusar um veículo de comunicação, ou um jornalista, usa-se sempre a forma mais abrangente e não a forma exata que é a adjetivação "sensacionalista". E vai além:

Por ser um termo totalitário, muitas vezes somos levados à imprecisão. E assim, passa-se a entender sensacionalismo através dos exageros que o jornal, o programa ou o meio de comunicação pratica tanto na divulgação de informações, ou na coleta de dados que de alguma maneira vem a desequilibrar o programa, ou o jornalístico (ANGRIMANI, 1995, p. 86-87).

\section{O propósito do jornalismo sensacionalista}

Na revista Comunicaşão e Sociedade, Peruzzo afirma que sempre existiram jornais regionais, no entanto, eram curtos e sempre reproduziam conteúdos de sua matriz nacional, e reforça: 
[...] a produção local e regional nunca esteve ausente dos meios de comunicação, seja televisivo ou não. [...] a televisão reserva espaços para a produção local embora sejam muito pequeno em relação ao número de horas no ar. [...] e que sejam majoritariamente destinados a "noticiários" (PERUZZO, 2005, p. 67-84).

Logo, percebe-se que o jornalismo sensacionalista regional/ local nasce com o intuito de cativar, conquistar e manter a audiência do público específico através da mistura de jornalismo sensacionalista e assistencialismo de baixo custo de produção, mas que gera excelentes números de audiência e grande faturamento. Como afirma Barbosa:

Situadas dentro de um regime capitalista, as empresas jornalísticas ou comunicação de massa estão submetidas à lei da oferta e da procura. Quando há concorrência, elas devem adequar sua programação à demanda da maioria do público. Por outro lado, banida a concorrência e instalado o monopólio, é possível ter controle sobre o gosto do público, atendendo aos interesses político, ideológico e mercadológico das elites que detém os meios de comunicação (BARBOSA, 2007, p. 17).

\section{O Código de Ética}

Segundo Marcondes Filho (2002), existem vacilos éticos condizentes a maneira de divulgar e comentar determinadas informações. E que, muitas vezes, as informações estão associadas ao desrespeito ao outro e possui até mesmo interesses próprios ou de conseguir um furo de reportagens, os meios de comunicação vivem de estímulos e de impactos que podem causar na sociedade. Deste modo, propomos uma discussão relacionada ao cumprimento dos preceitos que envolvem o Código de ética dos Jornalistas.

Criado em 1987, o primeiro Código de Ética genuinamente brasileira, vigorou até 2007, ano que foi atualizado perante o Congresso 
Extraordinário realizado pela classe na cidade de Vitória no Espírito Santo. O atual documento cita normas e posturas que deverão ser adotas por profissionais da comunicação social, em especial, os jornalistas no que diz respeito à comunidade em que estão inseridos.

Segundo Thais Ferreira:

O ato de se reformular e atualizar o Código de Ética do Jornalismo brasileiro potencializa valores que são essenciais para o exercício de tal profissão, num momento em que os meios de informação são considerados como uma mídia com funções educativas, democrática e cidadã (FERREIRA, 2007).

Devido a isso, foram selecionadas duas condutas de profissionais da comunicação: uma regional, com a jornalista Millena Cunha, que na época era contratada da BAND Bahia, e a segunda com o apresentador Carlos Massa, o Ratinho, contratado do SBT. Foram escolhidos estes dois comportamentos, por entender que no primeiro, a repórter usa todo seu conhecimento de mundo para humilhar o jovem preso, e no segundo, o apresentador Ratinho critica a atitude de Valdomiro Santiago, chefe da Igreja Mundial do Poder de Deus. Assim sendo, seria pertinente que tais profissionais da comunicação observassem e praticassem tudo que está dentro do Código com maior cautela para que possam evitar, por exemplo, um direcionamento da opinião do próprio profissional. Além disso, em ambos os casos, tanto a repórter quanto o apresentador deveriam se atentar para não cometerem infrações penais do tipo: injúria, calúnia e difamação.

No Código Penal Brasileiro, o parágrafo $3^{\circ}$ do artigo 140 afirma que a injúria consiste na utilização de elementos referentes à raça, cor, etnia, religião, origem, condição social ou humana, que, de forma a ofender a dignidade alheia, poderá resultar na pena de até três anos de reclusão social ao praticante do ato. Já o crime de difamação acontece quando alguém é acusado falsamente por um ato que não cometera, e a pena é de até dois anos de reclusão e multa em quem acusa. 


\section{O caso do jornalístico Brasil Urgente Bahia}

$\mathrm{Na}$ reportagem "Chororô na delegacia: acusado de estupro alega inocência", a jornalista Mirella Cunha, em pleno departamento policial, entrevista o jovem Paulo Sérgio Silva Souza, na ocasião, detido por acusação de estupro.

Além da abordagem indesejada que repórteres de programas possuem, com suas afirmações e vontade de que o suspeito confesse em frente à câmera, um crime que afirmara não cometer. Na reportagem, Mirella aborda e intimida o jovem que, devido ao seu baixo nível de escolaridade, não sabe pronunciar a palavra "próstata". Assim sendo, a profissional começa a debochar do acusado e, por várias vezes, pede ao jovem que repita a palavra. Começam, assim, longos e cansativos três minutos de horror e desrespeito da televisão baiana, quiçá do Brasil.

Angrimani (1995) afirma que:

O tom irado, sádico e implacável, transforma as palavras em instrumentos de flagelação, castigando as pulsões transgressoras. $\mathrm{O}$ jornal não deve ser visto aqui como simples meios de informação. [...] A reportagem parece insatisfeita com sua situação meramente informativa e extrapola suas funções. (ANGRIMANI, 1995, p. 118).

Segundo Freud (1981), imitar, disfarçar, caricaturar, parodiar e colocar a pessoa que está se tratando em uma situação cômica, está a serviço de "tendências hostis e agressivas" e visa apenas a retirar da pessoa toda "autoridade, dignidade, consideração e respeito". Durante as gravações, a repórter esnoba, ri e debocha das respostas e do choro do, até então, suspeito, expondo e condenando antecipadamente o detido. Tal gravação repercutiu na imprensa brasileira e também entre as redes sociais, e não demorou aos órgãos representantes de entidades sociais acionarem a Justiça, a fim de que todos os profissionais envolvidos na matéria fossem intimados e esclarecessem os motivos que levaram à violação dos direitos constitucionais. Como mostra a nota da Defensoria Pública do Estado da Bahia sobre o caso Mirella Cunha: 
Estiveram presentes hoje (quarta-feira), na $12^{\mathrm{a}}$ Delegacia Circunscricional de Polícia de Itapuã, em Salvador, os defensores públicos Fabiana Miranda e Rodrigo Assis para acompanhar o caso do acusado de assalto e estupro Paulo Sérgio Silva Sousa, de 18 anos. O fato está sendo apurado em ação penal que tramita na $8^{a}$ Vara Crime. Ao ser entrevistado por uma repórter do programa "Brasil Urgente Bahia", da Rede de TV Bandeirantes, o jovem nega o estupro. No entanto, a reportagem, a jornalista afirma que ele "não estuprou, mas queria estuprar", em seguida, o ridiculariza por confundir exame de corpo de delito com exame de próstata, ele chora e ela o chama de estuprador. O caso ganhou repercussão nacional desde ontem (terça-feira), contudo, o acusado foi preso no dia 31 de março e, desde então, está preso na Delegacia de Itapuã. A entrevista em questão foi realizada dois dias após sua prisão. De acordo com a defensora pública e subcoordenadora da Especializada de Proteção aos Direitos Humanos da Defensoria Pública do Estado da Bahia, Fabiana Miranda, os direitos da personalidade são essenciais à vida humana e visam a preservação de sua dignidade, bem jurídico inerente ao ser humano. "A honra e a imagem são direitos da personalidade, sendo inatos, inseparáveis da pessoa, não podendo o ser humano se privar deles", declarou. [...] Ainda de acordo com a defensora pública, a reportagem utilizou a imagem do acusado para humilhá-lo, achincalhá-lo, expô-lo ao ridículo, apenas com o intuito de utilizá-lo em uma tentativa de angariar audiência, de forma sensacionalista, às custas da violação da sua dignidade: "A repórter não se limitou ao dever de informar, atingiu cabalmente a honra, a dignidade e a imagem do detido". [...] O detido já conta com a assistência jurídica, o que deslegitima a Defensoria Pública da Bahia a adotar qualquer medida. "Viemos aqui para ver as condições em que se encontra Paulo Sérgio e oferecer nossos serviços, pois a Defensoria é uma instituição que está a disposição de todo cidadão em situação de vulnerabilidade. Outra questão importante é que não é possível conceber a devida justiça neste caso sem uma ação por danos morais. As imagens confirmam o abuso no exercício da informação e da manifestação do pensamento da repórter. A reportagem violou a Constituição Federal em seu inciso artigo $5^{\circ}$, inciso X", afirmou o defensor público Rodrigo Assis. [...] Paulo Sérgio é réu primário, vive nas ruas desde criança, apesar de ter residência em Cajazeiras 11. Tem seis irmãos, é analfabeto 
e já vendeu doces e balas dentro de ônibus. Ao ser questionado sobre como se sentiu durante a entrevista, ele diz: "Eu me senti humilhado, porque ela ficou rindo de mim o tempo todo. Eu chorei porque sabia que ali, eu iria pagar por algo que não fiz, e que minha mãe, meus parentes e amigos iriam me ver na TV como estuprador, e eu sou inocente" (RODRIGUES, 2014).

Durante a reportagem, pôde ser percebido que o conteúdo foi exibido em um programa "Ao Vivo", mas que fora pré-gravado, e o apresentador poderia evitar os excesso e abusos. Porém, o que aconteceu foi à exibição dos mais de três minutos de pura humilhação e a repercussão que, certamente, a produção do jornal sensacionalista almeja: a repercussão do fato, a audiência, e o faturamento, mesmo que para isso, os meios de comunicação e os profissionais envolvidos precisem violar os direitos do cidadão.

[...] Os meios de comunicação se utilizam da prerrogativa da proibição da censura pela Constituição Federal, o que garante a liberdade de informação jornalística, para manipular fatos, impor opiniões e influenciar a população. Ao agir dessa maneira, a mídia, ao retratar acontecimentos criminais, viola outras garantias igualmente constitucionais, invadindo privacidades, presumindo culpas e decretando inocências. Provoca uma colisão de direitos fundamentais que se harmoniza utilizando-se o Princípio da Proporcionalidade, a depender do caso concreto (MELLO, 2010, p. 106).

De acordo com o artigo $9^{\circ}$ do Código de Ética dos Jornalistas Brasileiros, no que diz respeito ao meio de comunicação e aos profissionais da comunicação social, em especial, aos jornalistas, "a presunção de inocência é um dos fundamentos da atividade jornalística".

A propósito, esse artigo nada mais faz do que aplicar ao âmbito jornalístico o Princípio da Presunção de Inocência, previsto no artigo quinto, inciso LVII da Constituição; bem como no item um do artigo XI da Declaração Universal dos Direitos Humanos. Ademais, na matéria exposta, percebe-se que houve enorme despreparo da jornalista, ao 
passo que houve o inescrupuloso objetivo do jornal de alimentar uma ideologia autoritária.

\section{Segundo Souza Netto:}

Para isso, a notícia veiculada deve obedecer aos critérios da verdade e do interesse público (entendido, neste caso, como de interesse social e não como uma exigência do público). Do contrário, versando sobre fatos sem importância, não há que se falar em direito à liberdade de informação jornalística, pois levada ao rigor, a informação não teria qualquer caráter jornalístico, apresentando, no mais das vezes, caráter meramente especulatório e contraditório como fundamento constitucional da dignidade da pessoa humana, ao se converter direitos individuais em diversão e entretenimento (SOUZA NETTO apud MORAES, 2005, p. 21).

Denis Moraes vai além, ao afirmar que:

[...] Assim, a divulgação pela imprensa de fatos ou notícias que não demonstram nenhuma finalidade pública e caráter jornalístico e que acarretam danos à dignidade humana pode resultar na prévia proibição da matéria, além de possível responsabilidade posterior em virtude do abuso no exercício do direito à informação (MORAES, 2006, p. 23).

De acordo com o Artigo $6^{\circ}$ sexto e inciso XVI, do Código de Ética, tanto a repórter quanto a emissora e os profissionais envolvidos na matéria omitiram-se aos preceitos de combater perseguições e discriminações por vários motivos, dentre eles raciais, econômicos e sociais. O Artigo 2, inciso XI, estabelece que jornalistas não podem divulgar informações de caráter mórbido, sensacionalista ou contrário aos valores humanos especialmente no que diz respeito à cobertura de crimes e/ou acidentes, e que todos os adjetivos veiculados na matéria podem ser enquadrados como infração dentro do Código de Ética até o momento citado. 


\section{Programa de entretenimento: O caso do Programa do Ratinho do SBT}

Em 11 de novembro de 2011 foi ao ar mais um Programa do Ratinho pelo SBT. Durante os minutos finais do programa, enquanto se apresentava o popular quadro do "Jornal Rational" (uma espécie de paródia do Jornal Nacional, transmitido pela Rede Globo), foi apresentado o sub-quadro denominado "Passa de Novo". Neste subquadro, o apresentador Carlos Massa, nacionalmente conhecido por "Ratinho", atendeu ao pedido de Lívia Piva, de Jaguaré (distrito localizado na zona oeste da cidade de São Paulo). A suposta telespectadora solicitou que a produção do programa exibisse um vídeo no qual um fiel da Igreja Mundial do Poder de Deus afirma ter quitado uma dívida no valor de R \$18 mil passando uma "toalhinha milagrosa" na fechadura do banco e, no dia seguinte, a dívida que ele tinha com o banco já não existia. A toalha à qual se refere é distribuída em encontros denominados "Sê Tu Uma Benção", realizados pela igreja supracitada, para que seus fieis e demais participantes alcancem bênçãos.

Num dado momento, o apresentador Ratinho brinca com o depoimento do fiel e, logo após, tece comentários sobre a conduta de alguns pastores, dando enfoque ao Bispo Valdomiro Santiago, afirmando: "Que absurdo alguns pastores de igrejas fazem! Isso é chamar a população de idiota. Quem é o idiota que vai acreditar numa mentira dessas?".

O momento crítico da opinião acontece quando o apresentador afirma que o bispo Valdomiro Santiago estaria enganando e roubando aos fieis, e acusa o religioso de estelionato. Segundo o Título II, Capítulo VI, Artigo 171, o Código Penal Brasileiro define estelionato como o ato de obter, para si ou para outrem, vantagem ilícita em prejuízo alheio, induzindo ou mantendo alguém em erro, mediante artifício ardil ou qualquer outro meio fraudulento. $\mathrm{O}$ apresentador vai além e ameaça o suposto líder, afirmando que caso houvesse uma ação jurídica contra sua pessoa, o mesmo o procuraria para uma séria conversa. Ato que pode 
ser considerado como ameaça, já que o Código Penal Brasileiro entende que no decreto de LEI n².848, de 07/12/1940, aponta que o crime de "Ameaça" pode ser enquadrado no art.147, sendo um dos delitos que tratam das transgressões contra a liberdade individual.

No que diz respeito ao Código de Ética da Comunicação Social, percebe-se que uma transgressão do Artigo $6^{\circ}$, inciso VIII, que reafirma que o profissional da Comunicação Social, em especial jornalistas, deve respeitar o direito à intimidade, "à privacidade, à honra e à imagem do cidadão” (grifo nosso). Já no Artigo 12 e inciso II diz que devemos tratar com respeito todas as pessoas mencionadas nas informações a serem divulgadas.

Ainda sobre o Código de Ética dos jornalistas, também é possível identificar que o Artigo $6^{\circ}$ indica ser dever do profissional combater a prática de perseguição e discriminação por motivos sociais e religiosos, dentre outros.

Também foi possível perceber que, mesmo dentro de um quadro e sub-quadro de humor, e apesar das críticas ferrenhas, o programa não abre espaço para que especialistas discutam o assunto em questão.

O debate só aconteceu através dos comentários feitos pelos leitores na Coluna de Heloísa Tolipan, no site do Jornal do Brasil, e pelos visualizadores do vídeo no canal do YouTube, confirmando o que foi exposto no programa radiofônico do Observatório da Imprensa de 03 de junho de 2014, no qual Luciano Martins Costa argumenta que "A imprensa é veículo de mão única, a serviço de uma visão de mundo específica e avessa ao contraditório". E conclui:

$\mathrm{Na}$ comunicação de massa, onde esse comércio de ideias se dá de forma massiva, o que ocorre é um jogo de convencimento, no qual os emissores procuram estabelecer os paradigmas para a compreensão da realidade. Aqueles que discordam desses paradigmas não podem, por exemplo, usar as rotativas dos jornais ou as câmeras e sistemas de difusão da televisão para expor suas opiniões. A resposta se dá em outros meios, e o meio onde foi postada a mensagem original segue com seu discurso unívoco (MARTINS, 2014). 


\section{Considerações finais}

Aplicado o Código de Ética nas duas abordagens, pôde-se perceber que o Código de Ética do Jornalismo possibilita diferentes interpretações sobre determinados artigos. O inciso I do artigo 2, por exemplo, afirma que a divulgação de informações deve acontecer de forma precisa e correta, independente do meio a ser veiculado, porém o Código de Ética não deixa claro quais seriam os parâmetros de definição do que pode ser considerado um relato jornalístico "preciso" e "correto". No inciso XIV do artigo $\sigma^{a}$ não é diferente, pois afirma que é dever do jornalista promover a liberdade e o direito igualitário, ou seja, é dever do jornalismo combater a prática de perseguição e discriminação por motivos sociais, econômicos políticos, religiosos, raciais, dentre outros. Desta forma, afirmamos que a nossa análise qualitativa não reflete de forma peremptória as transgressões contidas em ambas as análises.

Apesar de cada emissora e programa de jornalismo ou entretenimento trazer uma ideologia que se caracteriza como a marca do canal/emissora, como afirma Orlandi (2002), reconhecemos que a objetividade e a neutralidade não estão presentes dentro do jornalismo.

Tanto repórter quanto apresentador deveriam se defender utilizando preceitos do próprio Código de Ética, baseando-se unicamente nos incisos I e $\mathrm{X}$ do artigo $6^{\circ}$. $\mathrm{O}$ inciso I indica que o jornalismo não deve se opor ao arbítrio, ao autoritarismo e à opressão, dentre outros, mas deve defender os princípios expressos na Declaração dos Direitos Humanos. Já no inciso X, consta que é dever do jornalista defender e garantir os princípios constitucionais, legais, baseados no Estado Democrático de Direito. Logo, os profissionais e emissoras envolvidas deveriam se contrapor aos possíveis comentários afirmando que estavam defendendo os princípios fixados pelo Código de Ética, contudo a defesa não serviria para explicar o excesso de adjetivos, acusações e imposições de teor sensacionalista.

Por fim, cabe aos profissionais da comunicação fazer suas próprias reflexões sobre o Código de Ética e como fazê-lo de parâmetro, 
dentro da prática profissional do campo da comunicação jornalística e de entretenimento, uma vez que o Código possui Artigos e incisos passíveis de múltiplas interpretações e tantos outros divergentes.

É entendido que o nosso Código de Ética possui validade no que diz respeito a traçar os fundamentos da prática da comunicação social, seja ela voltada exclusivamente para atender aos interesses da população local ou não. Vale salientar ainda que todo Código de Ética e o Código Penal possuem falhas e devem ser aprimorados constantemente, de acordo com grandes e rápidas mudanças que a sociedade vem apresentando.

\section{Referências}

ANGRIMANI, Danilo. Espreme que sai sangue: um estudo do sensacionalismo na imprensa. São Paulo: Sumus, 1995.

BARBOSA, Marcelo Araújo. Violência e sensacionalismo na televisão brasileira: um estudo do Linha Direta. 2007. Monografia (Trabalho de conclusão do curso de Comunicação Social), UFJF, Juiz de Fora, 2007.

BOURDIEU, Pierre. Sobre a televisão. Rio de Janeiro: Zahar, 1997.

FERREIRA, Aurélio Buarque de Holanda. Dicionário Aurélio Básico da Lingua Portuguesa. Rio de Janeiro: Nova Fronteira, 2005.

FERREIRA, Thais. Prática jornalistica: a importância do Código de Ética. 28/08/2007. Disponível em: <http://www.observatriodaimprensa. com.br/artigos.asp?cod=448CID002 > . Acesso em: 03 jul. 2014.

FREUD, Sigmund. Obras Completas. Madrid: Biblioteca Nova, 1981.

MARCONDES FILHO, Ciro. O capital da notícia. São Paulo: Ática, 1986. . A saga dos cães perdidos. 2. ed. São Paulo: Hacker Editores, 2002.

MARTINS, Luciano C. Artes do ofício: resposta a um jovem jornalista. Observatório da Imprensa, 16 de julho de 2014. Disponível em: $<$ http://www.observatoriodaimprensa.com.br/news/view/resposta_a_ um_jovem_jornalista $>$. Acesso em: 14 jul. 2014. 
MELLO, Carla Gomes de. Mídia e crime: liberdade de informação jornalística e presunção de inocência. Revista de Direito Público, Londrina, v. 5, n. 2, p. 106, ago. 2010. Disponível em: <http://www.uel.br/ revistas/uel/index.php/direitopub/article/view/7381/6511>. Acesso em: 15 jul. 2014.

MORAES, Alexandre de. Direito constitucional. 19. ed. São Paulo: Atlas, 2006.

MORAES, Renata. O Anjo e o Monstro. Veja São Paulo, São Paulo: Editora Abril, 2005.

MOREIRA, Denis. O poder criminalizante da mídia no processo penal: uma análise sob a perspectiva de um processo justo. 2006. Monografia (Conclusão do curso de Direito) - UFJF, Juiz de Fora, 2006.

ORLANDI, Eni P. Análise de discurso. Princípios e procedimentos. Campinas: Pontes, 2002.

PEDROSO, Rosa Nívea. A produção do discurso de informação num jornal sensacionalista. In: COMUNICAÇÃO PARA A CIDADANIA; CONGRESSO BRASILEIRO DE CIÊNCIAS DA COMUNICAÇÃO, 26., 2003, Belo Horizonte. Anais... São Paulo: INTERCOM, 2003. p. 1-23. 1 CD-ROM.

PERUZZO, Cicília M. K. Mídia local e suas interfaces com a mídia comunitária. In: RODRIGUES, Cathy. Defensoria apura situação de jovem entrevistado por repórter da Band. Defensoria Pública do Estado da Bahia, 23 de maio de 2012. Disponível em: <http://www.defensoria.ba.gov. $\mathrm{br} /$ portal $/$ index.php? site $=1 \&$ modulo $=$ eva_conteudo\&cocod $=7385>$. Acesso em: 16 jul. 2014. 